\title{
Serum albumin fragmentation in end-stage renal disease patients - a pilot study
}

\author{
Elena Donadio ${ }^{1}$, Francesco Piccolomini ${ }^{2}$, \\ Veronica Dimuccio ${ }^{2}$, Antonio Felicioli ${ }^{1}$, Ettore \\ Balestreri $^{2}$, Riccardo Cianti ${ }^{3}$, Alessandro \\ Armini $^{3}$, Luca Bini ${ }^{3}$, Romano Felicioli ${ }^{1}$ and \\ Carlo Donadio ${ }^{4, *}$ \\ ${ }^{1}$ Department of Veterinary Anatomy, Biochemistry \\ and Physiology, University of Pisa, Pisa, Italy \\ ${ }^{2}$ Biophysics Institute, CNR, Pisa, Italy \\ ${ }^{3}$ Department of Molecular Biology, University of \\ Siena, Siena, Italy \\ ${ }^{4}$ Department of Internal Medicine - Nephrology, \\ University of Pisa, Pisa, Italy
}

\begin{abstract}
Background: The goal of this study was to detect modification in the expression of plasma proteins and/or post-translational modifications of their structure in patients with end stage renal disease.

Methods: Serum samples from 19 adult patients treated by maintenance hemodialysis (MHD) were analyzed in comparison to sera from six healthy controls using sodium dodecylsulfate-polyacrylamide gel electrophoresis (SDS-PAGE) and two-dimensional electrophoresis (2DE). Spots of interest were identified by mass spectrometry analysis. In addition, the $2 \mathrm{DE}$ maps were incubated with a human anti-albumin polyclonal antibody.

Results: SDS-PAGE gels, 2DE maps and matrix-assisted laser desorption/ionization time of flight analysis indicated over-expression of low-molecular weight proteins (LMWP) in sera from patients. Unexpectedly, another 15 spots with estimated $\mathrm{M}_{r}$ of $12.5-29 \mathrm{kDa}$ from the 2DE maps of six patients were identified as fragments of albumin. 2D immunoblotting of sera from 12 other patients detected numerous albumin fragments.

Conclusions: These results indicate that in addition to increased expression of LMWP, a relevant amount of albumin fragments are detectable in the serum of patients undergoing MHD. Uremia appears to facilitate the fragmentation of albumin and/or the retention of albumin fragments in blood.
\end{abstract}

Clin Chem Lab Med 2009;47:1373-9.

*Corresponding author: Prof. Carlo Donadio, Dipartimento di Medicina Interna, Nefrologia, Via Roma 67, 56100 Pisa, Italy

Phone: + 39050 553414, Fax: + 39050997278 ,

E-mail: c.donadio@med.unipi.it

Received May 19, 2009; accepted July 26, 2009;

previously published online September 25, 2009
Keywords: albumin fragments; immunoblotting; lowmolecular weight proteins; matrix-assisted laser desorption/ionization time of flight mass spectrometry; plasma proteomics; uremic syndrome.

\section{Introduction}

The kidney plays a central role in the regulation of plasma concentrations of low-molecular weight proteins (LMWP) and human serum albumin (HSA). In particular, the kidney determines the rate of plasma metabolic clearance of LMWP. These proteins are filtered from the plasma through renal glomeruli with a high filtration coefficient. Following filtration, LMWP are reabsorbed by proximal tubular cells through the brush border via endocytosis and are accumulated inside tubular cells where they are completely catabolized $(1,2)$. Plasma clearance of many LMWP [cystatin C, lysozyme, $\beta_{2}$-microglobulin, $\alpha_{1}$-microglobulin (AMBP), $\beta$-trace protein, chromogranin] depends upon the glomerular filtration rate (GFR) (3-9). In patients with end-stage renal disease (ESRD), decreased GFR leads to increases in the plasma concentration of some LMWP (i.e., parathormone, $\beta_{2}$-microglobulin, and probably others not yet discovered). These proteins, together with other uremic toxins may cause the uremic syndrome. Hemodialysis, the most common treatment for uremic syndrome, cannot completely clear all accumulated uremic toxins from the blood, in particular those with a molecular weight $>1000 \mathrm{Da}$. The persistent increase in the serum concentrations of some uremic toxins (i.e., $\beta_{2}$ microglobulin) is a determinant of dementia and amyloidosis which may occur in maintenance hemodialysis (MHD) patients. HSA has important physiological functions, such as the maintenance of plasma oncotic pressure, transport of hormones and other biological compounds and xenobiotics, and antioxidant proprieties. Recent studies demonstrated that the urine of diabetic patients has a high prevalence of HSA fragments (10). Recently, it has been demonstrated that oxidative stress increases fragmentation and carbonylation of plasma and urinary albumin, and also determines alteration in the redox state of HSA (11). Inflammation, common in MHD, can lead to fragmentation of HSA through a marked increase in serum proteases. Thus, it is possible to hypothesize that post-translational modifications to HSA can occur in patients with ESRD. 
The goal of this study was to evaluate the utility of a proteomic analysis of serum from patients undergoing MHD to identify alterations in the expression of LMWP and/or modifications to the structure of HSA.

\section{Patients and methods}

\section{Study design}

Proteomic analysis, by means of sodium dodecylsulfatepolyacrylamide gel electrophoresis (SDS-PAGE), twodimensional electrophoresis (2DE), immunoblotting and matrix-assisted laser desorption/ionization time of flight mass spectrometry (MALDI-TOF) analysis, was performed using serum collected from MHD patients, and compared with normal subjects. MHD patients were in stable clinical condition and undergoing treatment for at least 6 months at a University-based hemodialysis clinic. Blood samples were collected from MHD patients prior to the start of dialysis. Blood samples were also collected by healthy fasting individuals. All samples were prepared according to Aresta et al. (12). Briefly, they were collected in iced tubes from patients with ESRD at the start of a dialysis session, and before breakfast from controls. Samples from patients and controls were centrifuged within $30 \mathrm{~min}$ after clotting and the sera stored at $-20^{\circ} \mathrm{C}$ until analysis.

\section{Patients}

Nineteen adult patients (F7, M12; 32-88 years, mean 67 ) with ESRD due to various renal diseases (chronic glomerulonephritis six patients; chronic kidney disease four patients; ischemic renal disease four patients; renal cancer, diabetes type 2, urinary tract malformation, interstitial nephritis, and Alport syndrome, one patient each). All patients were in stable conditions without evidence of current inflammatory disease and treated with MHD (hemodialfiltration, bicarbonate dialysis or acetate-free biofiltration) for more than 6 months. Six normal subjects (F4, M2; aged 28-60 years, mean 38.4) were used for comparison. The size of this pilot investigation was limited by the complexity of the proteomic analysis. The study was approved by the institutional Ethical Committee and conducted in accordance with Helsinki declaration. Patients gave their informed consent.

\section{Laboratory methods}

SDS-PAGE An aliquot of $0.15 \mu \mathrm{L}$ of serum (10 $\mu \mathrm{g}$ of proteins) underwent SDS-PAGE according to the procedure of Laemmli (13) using $12 \%$ or $15 \%$ T separating polyacrylamide gels and a Miniprotean II (Bio-Rad Laboratories, Hercules, CA, USA). Gels underwent silver staining using a MALDI-TOF compatible protocol, according to Yan and co-authors (14).

Two-dimensional electrophoresis 2DE was performed according to Görg and co-authors (15). Briefly, an aliquot corresponding to $80 \mu \mathrm{g}$ of sample was mixed with $240 \mu \mathrm{L}$ of rehydration buffer containing $8 \mathrm{M}$ urea, $2 \%$ CHAPS, $1 \mathrm{mM}$ DTT, $0.8 \%$ IPG buffer pH 3-10, 0.8\% Pharmalyte pH 3-10, and a trace of bromophenol blue. Serum samples were loaded onto an $11 \mathrm{~cm}$ Immobiline DryStrip, pH 3-10 immobilized $\mathrm{pH}$ gradient DryStrips, or on an $11 \mathrm{~cm}$ Immobiline DryStrip, pH 3-5.6 immobilized pH gradient DryStrips (GE Healthcare Bio-Sciences, Uppsala, Sweden). Isoelectric Focusing was performed with the Multiphor II apparatus (GE Healthcare Bio-Sciences, Uppsala, Sweden) for $45,000 \mathrm{Vh}$ at $15^{\circ} \mathrm{C}$, then equilibrated for $8 \mathrm{~min}$ in $50 \mathrm{mM}$ Tris- $\mathrm{HCl}, \mathrm{pH} 8.8$, containing
$30 \% \mathrm{~V} / \mathrm{V}$ glycerol, $6 \mathrm{M}$ urea, $4 \% \mathrm{SDS}, 2 \% \mathrm{~m} / \mathrm{V}$ DTT, and finally for $12 \mathrm{~min}$ in $50 \mathrm{mM}$ Tris- $\mathrm{HCl}$, pH 6.8, containing $30 \% \mathrm{~V} / \mathrm{V}$ glycerol, $6 \mathrm{M}$ urea, $4 \% \mathrm{SDS}$ and $2.5 \% \mathrm{~m} / \mathrm{V}$ iodoacetamide and trace of bromophenol blue. Second dimension electrophoresis was performed using $12 \%$ or $15 \% \mathrm{~T}, 2.6 \% \mathrm{C}$, separating polyacrylamide gels ( $1 \mathrm{~mm}$ tick) according to Laemmli (13) but without stacking gels, using a Hoefer SE 600 system (GE Healthcare Bio-Sciences, Uppsala, Sweden). The electrophoretic run was performed according to the manufacturer's instructions at $30 \mathrm{~mA}$ per gel at $9^{\circ} \mathrm{C}$ for $3 \mathrm{~h}$ and $30 \mathrm{~min}$, leaving the voltage free to vary. Before performing 2D-electrophoresis, serum samples were divided in two aliquots. One aliquot underwent HSA depletion using a $\mathrm{Hi}$ Trap blue HP (GE Healthcare Bio-Science, Uppsala, Sweden) column following the manufacturer's instructions. HSA depletion was performed to increase the sensitivity for low-abundance proteins.

Gels were scanned with an Epson Expression 1680 Pro scanner and images were analyzed with PDQuest $V$ 6.2.1. (Bio-Rad Laboratories, Hercules, CA, USA).

Matrix-assisted laser desorption/ionization time of flight mass spectrometry and database search Spots of interest were excised from the $2 \mathrm{DE}$ gel and destained overnight with a solution of $25 \mathrm{mM}$ ammonium bicarbonate, $50 \%$ acetonitrile. The proteins were digested in-gel with trypsin as described by Hellman et al. (16). Protein identification was performed using peptide mass fingerprinting with an Ettan MALDI-TOF Pro mass spectrometer (GE Healthcare Bio-Sciences, Uppsala, Sweden) as described previously $(16,17)$. From each protein digest, $0.75 \mu \mathrm{L}$ of matrix solution (satured solution of alpha-cyano-4-hydroxycynnamic acid in $50 \%$ acetonitrile and $0.5 \%$ trifluoroacetic acid) was spotted onto the MALDI target and allowed to dry. After tryptic peptide mass acquisition, mass fingerprinting searching was performed using Swiss-Prot/TrEMBL and NCBInr databases with MASCOT (Matrix Science Ltd., London, UK, http://www. matrixscience.com). A mass tolerance of $50 \mathrm{ppm}$ was used and the number of accepted missed cleavage sites was set to one. Alkylation of cysteine by carbamidomethylation was assumed as a fixed modification, while oxidation of methionine was considered as a possible modification. The criteria used to accept identifications included the extent of sequence coverage, number of matched peptides and probabilistic scores. By default, the significance level was set at $5 \%$.

Immunoblotting After 2DE, proteins on the gel were transferred electrically to a polyvinylidene difluoride membrane (Hybond-P PVDF, Amersham Biosciences, Piscataway, NJ, USA) using a Pharmacia LKB Nova Blot (GE Healthcare BioSciences, Uppsala, Sweden) semi-dry transfer apparatus and using the Towbin buffer. According to Towbin's protocol, a constant current of $0.8 \mathrm{~mA} / \mathrm{cm}^{2}$ gel was applied for $1 \mathrm{~h}$ at room temperature, leaving the voltage free to vary. The membrane was saturated for $1 \mathrm{~h}$ at room temperature with $3 \%$ skim milk in PBS. This was followed by an overnight incubation at $4{ }^{\circ} \mathrm{C}$ with Polyclonal Anti-Human HSA serum (DakoCytomation, Glostrup, Denmark) at 1:1000 dilution in PBS under mild shaking. After three washings in $0.05 \%$ Tween in PBS, a $1 \mathrm{~h}$ incubation with 1:1000 diluted goat antirabbit IgG peroxidase conjugate antibody (Sigma-Aldrich, St. Louis, Missouri, USA) was followed by four washings in PBS. Color development was accomplished using a solution of $5 \mathrm{mM} 4$-chloro-1-naphtol, $6 \%$ methanol and $0.025 \%$ hydrogen peroxide in PBS solution. 


\section{Results}

SDS-PAGE of the 19 uremic sera indicated an increase in LMWP. In particular, bands corresponding to a molecular weight (MW) between 5 and $26 \mathrm{kDa}$ were observed (data not shown).

2DE of 12 patients, performed without HSA depletion in the range $3-10 \mathrm{pH}$, demonstrated an increase in the expression of LMWP between 14 and $24 \mathrm{kDa}$ when compared with control samples, where these spots are absent or present only in low amounts (Figure 1). 2DE of sera from two patients with ESRD, performed in the range 3-10 pl following depletion of HSA, demonstrated over-expression of different spots in the range of $6.5-29 \mathrm{kDa}$ (Figure 2). Similarly, 2DE of sera from two other patients, performed without HSA depletion in the range $3-5.6 \mathrm{pH}$, demonstrated over-expression of different spots in the range between 17 and $32 \mathrm{kDa}$ (Figure 3). MALDI-TOF analysis identified these spots ( $c-h$, Table 1 and Figure 3 ) as fragments of immunoglobulins, $\alpha_{1}$-microglobulin precursor, leukotriene A4 hydrolase variant, chain L crystal structure of Fab D3h44, retinol binding protein and transthyretin. Unexpectedly, 15 spots, analyzed by MALDI-TOF, and isolated from the gels performed in the range of $3-10 \mathrm{pH}$ with estimated $\mathrm{MW}$ ranging from 12.5 to $29 \mathrm{kDa}(1-15$, Table 1, Figures 1 and 2) were identified as fragments of HSA. In a

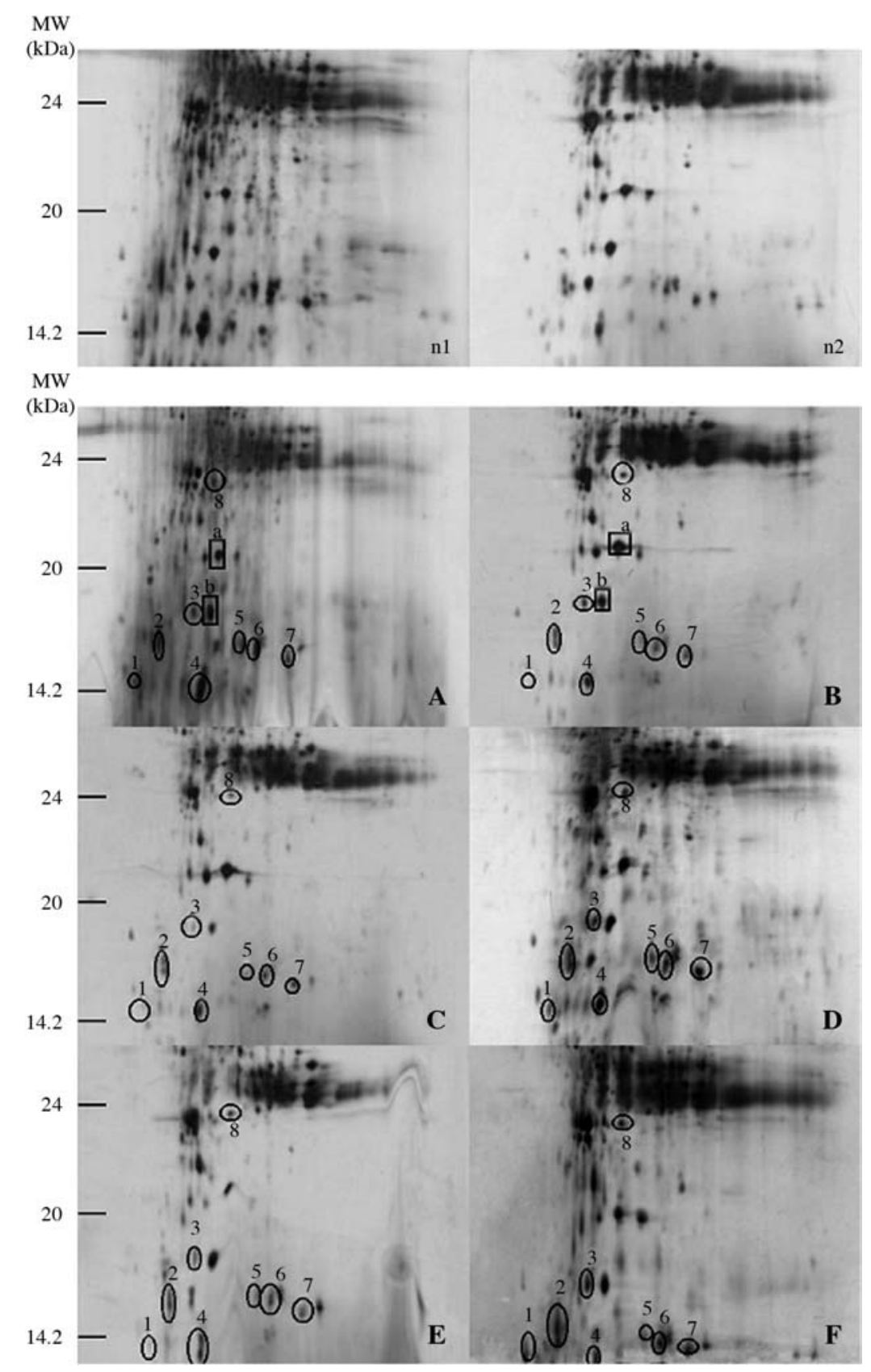

Figure 1 Silver stained 2DE of serum proteins belonging to 2 healthy controls $(n 1, n 2)$ and 6 patients affected by end-stage renal disease (ESRD).

Gels were run first using a $3-10 \mathrm{pH}$ gradient followed by SDS-PAGE. The spots are identified with numbers and letters corresponding to numbers and letters in Table 1. 


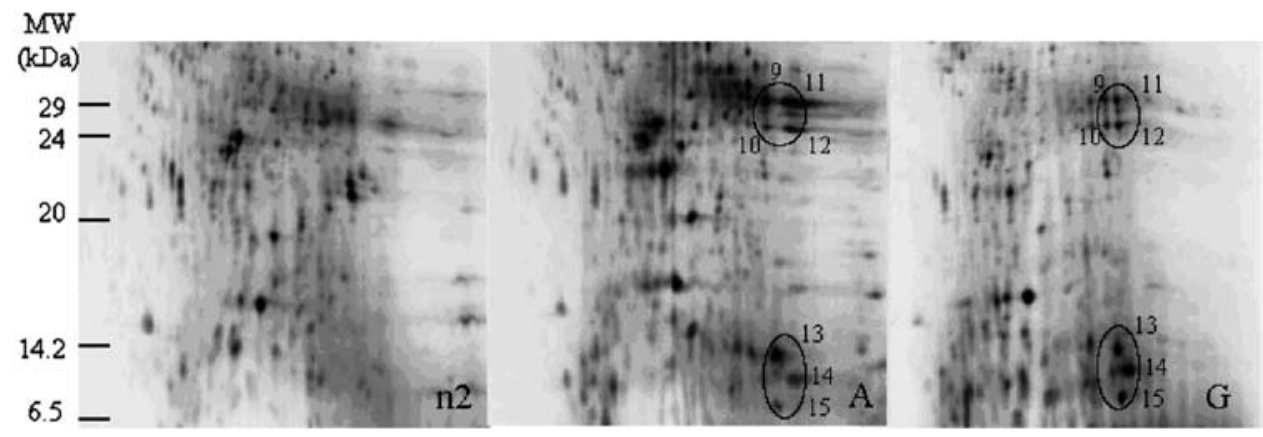

Figure 2 Silver stained 2DE of serum proteins belonging to a healthy control (n2) and two patients on maintenance hemodialysis.

Prior to electrophoresis, serum samples were depleted of albumin by use of Hi Trap blue HP (GE Healthcare). Gels were run first using a 3-10 pH gradient followed by SDS-PAGE. Spots are identified with numbers corresponding to numbers in Table 1 and Figure 4.

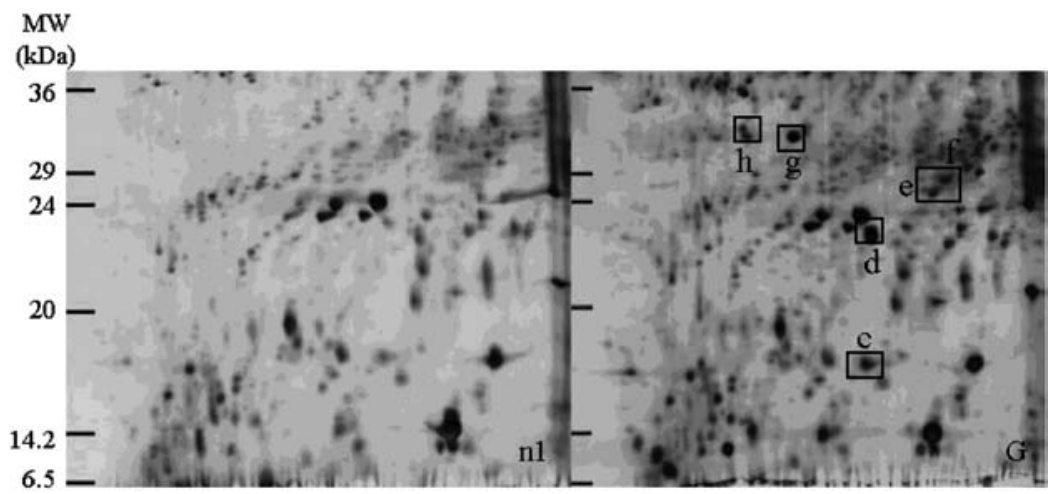

Figure 3 Silver-stained 2DE of serum proteins from a healthy control (n1) and a patient on maintenance hemodialysis. Gels were run first using a $3-5.6 \mathrm{pH}$ gradient followed by SDS-PAGE. The spots are identified with letters corresponding to those in Table 1.

young patient affected by the Prune Belly syndrome, the fragments were from different variant forms of HSA (the corresponding spots in Table 1 are indicated by an asterisk). The great majority of fragments of HSA were determined to be from the carboxy terminal part of the molecule, starting from amino acids 380-400 or 500-509 (Figure 4). In some cases, fragments originating from the $\mathrm{N}$-terminal part of the molecule of HSA were identified. The terminal amino acid of each fragment was Arginine or Lysine, indicating that the molecule was cleaved by a trypsin-like protease.

Immunoblotting performed using 12 sera from patients with uremia demonstrated the presence of several immunoreactive fragments of HSA ranging from 14 to $22 \mathrm{kDa}$. This was much greater than that seen in normal sera (data not shown).

\section{Discussion}

This study, performed in a small group of stable patients undergoing MHD, indicates that it is possible to identify over-expression of many LMWP in serum using proteomic techniques. In addition, proteomic analysis allowed for the detection of HSA fragments in serum of MHD patients.
The literature suggests that proteomics has the potential to detect new markers of renal disease and to unravel the pathophysiology of uremia (18). In particular, using gel electrophoresis in combination with mass spectrometry, 292 proteins have been identified in hemodialysis fluid. More than $70 \%$ of these proteins had not previously been identified in serum and more than $50 \%$ were LMWP, smaller than $40 \mathrm{kDa}$ (19). Thus, the increase in LMWP appears particularly relevant in ESRD. In our study, the removal of HSA and other abundant serum proteins resulted in a sample more concentrated in low abundance proteins that allowed the identification of LMWP. Furthermore, precise separation of the different spots on 2DE gels allowed us to identify either LMWP or HSA fragments which were obtained in the range of pl that we investigated.

The detection of HSA fragments in serum of patients with ESRD is the major novel finding in the present study. HSA fragments have been found previously in urine samples. In particular, the urine of diabetic patients has a high prevalence of immunounreactive HSA, whose structure consists of polypeptide chains held together by non-covalent and disulfide bonds (10). In the blood of type 1 diabetic patients with albuminuria, fragments of radio-labeled HSA have been found possibly deriving from HSA reab- 
Table 1 Serum proteins identified by mass spectrometry.

\begin{tabular}{|c|c|c|c|c|c|c|c|c|c|}
\hline $\begin{array}{l}\text { Figure } \\
\text { ref. }\end{array}$ & $\begin{array}{l}\text { Spot } \\
\text { name }\end{array}$ & $\begin{array}{l}\text { MW } \\
\text { observed, } \\
\mathrm{kDa}\end{array}$ & $\begin{array}{l}\text { pl } \\
\text { observed }\end{array}$ & $\begin{array}{l}\text { Matched } \\
\text { peptides }\end{array}$ & $\begin{array}{l}\text { Sequence } \\
\text { coverage, \% }\end{array}$ & $\begin{array}{l}\text { Mass, } \\
\mathrm{kDa}\end{array}$ & $\mathrm{pl}$ & Accession No. & ID name \\
\hline 1 & 1 & 14.5 & 4.62 & 6 & 10 & 71317 & 5.92 & P02768 & HSA precursor \\
\hline 1 & 2 & 16.6 & 4.89 & 7 & 9 & 71317 & 5.92 & P02768 & HSA precursor \\
\hline 1 & 3 & 17.8 & 5.77 & 6 & 10 & 71317 & 5.92 & P02768 & HSA precursor \\
\hline 1 & 4 & 14.4 & 5.93 & 6 & 9 & 71317 & 5.92 & P02768 & HSA precursor \\
\hline 1 & 5 & 16.1 & 6.68 & 5 & 9 & 71317 & 5.92 & P02768 & HSA precursor \\
\hline 1 & 6 & 15.5 & 6.82 & 7 & 11 & 71317 & 5.92 & P02768 & HSA precursor \\
\hline 1 & 7 & 15.2 & 7.37 & 4 & 8 & 71317 & 5.92 & P02768 & HSA precursor \\
\hline 1 & 8 & 25.6 & 5.95 & 7 & 8 & 71317 & 5.92 & P02768 & HSA precursor \\
\hline 2 & 9 & 29.0 & 7.00 & 9 & 18 & 71317 & 5.92 & P02768 & HSA precursor \\
\hline 2 & $10^{\mathrm{a}}$ & 25.0 & 7.02 & 8 & 16 & 71317 & 5.92 & P02768 & HSA, Variant maku \\
\hline 2 & $11^{\mathrm{a}}$ & 28.9 & 7.19 & 9 & 18 & 71317 & 5.92 & P02768 & $\begin{array}{l}\text { HSA, Variant coari I/ } \\
\text { Porto alegre }\end{array}$ \\
\hline 2 & $12^{\mathrm{a}}$ & 24.9 & 7.22 & 8 & 16 & 71317 & 5.92 & P02768 & $\begin{array}{l}\text { HSA, Variant coari I/ } \\
\text { Porto alegre }\end{array}$ \\
\hline 2 & $13^{a}$ & 14.7 & 7.20 & 6 & 11 & 71317 & 5.92 & P02768 & $\begin{array}{l}\text { HSA, Variant } \\
\text { church bay }\end{array}$ \\
\hline 2 & $14^{\mathrm{a}}$ & 13.8 & 7.38 & 7 & 11 & 71317 & 5.92 & P02768 & $\begin{array}{l}\text { HSA, Variant coari I/ } \\
\text { Porto alegre }\end{array}$ \\
\hline 2 & 15 & 12.5 & 7.28 & 8 & 16 & 71317 & 5.92 & P02768 & HSA precursor \\
\hline 1 & a & 21.4 & 6.21 & 3 & 14 & 45861 & 6.13 & P00738 & Haptoglobin precursor \\
\hline 1 & b & 18.1 & 6.05 & 7 & 72 & 15991 & 5.52 & P02766 & Transthyretin precursor \\
\hline 3 & c & 17.0 & 4.72 & 4 & 48 & 15991 & 5.52 & P02766 & Transthyretin precursor \\
\hline 3 & d & 22.4 & 4.72 & 8 & 56 & 23337 & 5.76 & P02753 & $\begin{array}{l}\text { Retinol-binding } \\
\text { protein precursor }\end{array}$ \\
\hline 3 & e & 24.8 & 5.04 & 4 & 31 & 23770 & 6.99 & gi|18655503 & $\begin{array}{l}\text { Chain L, Crystal } \\
\text { structure of Fab D3h44 }\end{array}$ \\
\hline 3 & $f$ & 27.2 & 5.09 & 4 & 28 & 24626 & 6.53 & gi|62089060 & $\begin{array}{l}\text { Leukotriene } \mathrm{A} 4 \\
\text { hydrolase variant }\end{array}$ \\
\hline 3 & g & 32.4 & 4.36 & 5 & 23 & 39986 & 5.95 & P02760 & $\begin{array}{l}\text { AMBP protein } \\
\text { precursor }\end{array}$ \\
\hline 3 & $\mathrm{~h}$ & 32.3 & 4.13 & 4 & 18 & 39986 & 5.95 & P02760 & $\begin{array}{l}\text { AMBP protein } \\
\text { precursor }\end{array}$ \\
\hline
\end{tabular}

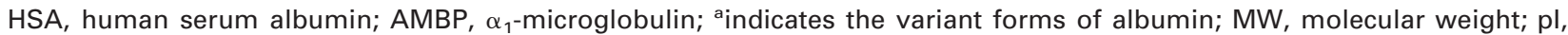
isoelectric point.

sorbed by proximal tubular cells before undergoing degradation (20). In addition, the presence of HSA fragments in urine of patients with idiopathic nephritic syndrome has been demonstrated (21). Low concentrations of HSA fragments were also found in the plasma of these same patients. Data from the literature indicate that fragmentation of HSA occurs in the urine, and possibly in the serum of diabetics and patients with proteinuria. Until now, no data were available regarding HSA fragments in the serum of MHD patients. Inflammation and oxidative stress are commonly present in patients undergoing MHD. In children affected by primary nephritic syndrome, structural analysis of plasma and urinary proteins has recently shown increased proteolysis of albumin, together with increased oxidative stress (22). We hypothesize that in uremic patients, oxidative stress (11) and possibly increased susceptibility to the action of some proteases induced by inflammation, may cause HSA fragmentation that we observed in our patients. This might be due to trypsin-like proteases. Analysis of the albumin fragments does not allow one to differentiate the cleavage products from those produced by trypsin. For HSA variants that we observed in one patient associated with greater HSA fragmentation, it is probable that the substitution of one amino acid (in particular Lys for Glu or Glu for Lys), which characterizes all the variations which we observed, determines alterations in charge, dimension and tertiary structure of HSA. These alterations may affect its susceptibility to oxidative stress and the action of proteases. Whatever the mechanism leading to the production of HSA fragments, it is expected that in subjects with normal renal function, HSA fragments circulating in the plasma are cleared from the plasma via glomerular filtration due to their low MW. We also hypothesize that since the GFR in many patients undergoing MHD is essentially zero, HSA fragments produced by the action of serum protease are retained in the plasma. These fragments accumulate and affect HSA binding abilities and antioxidant properties. However, the clinical relevance of fragmentation of HSA in serum of uremic patients is unknown. Also, the nature of fragmentation of albumin in sera from patients affected by different types of renal disease is unknown. This topic will be explored in further studies.

\section{Conclusions}

The serum proteome of patients with MHD is characterized by over-expression of proteins and protein fragments with a MW $<30 \mathrm{kDa}$, identified as low- 


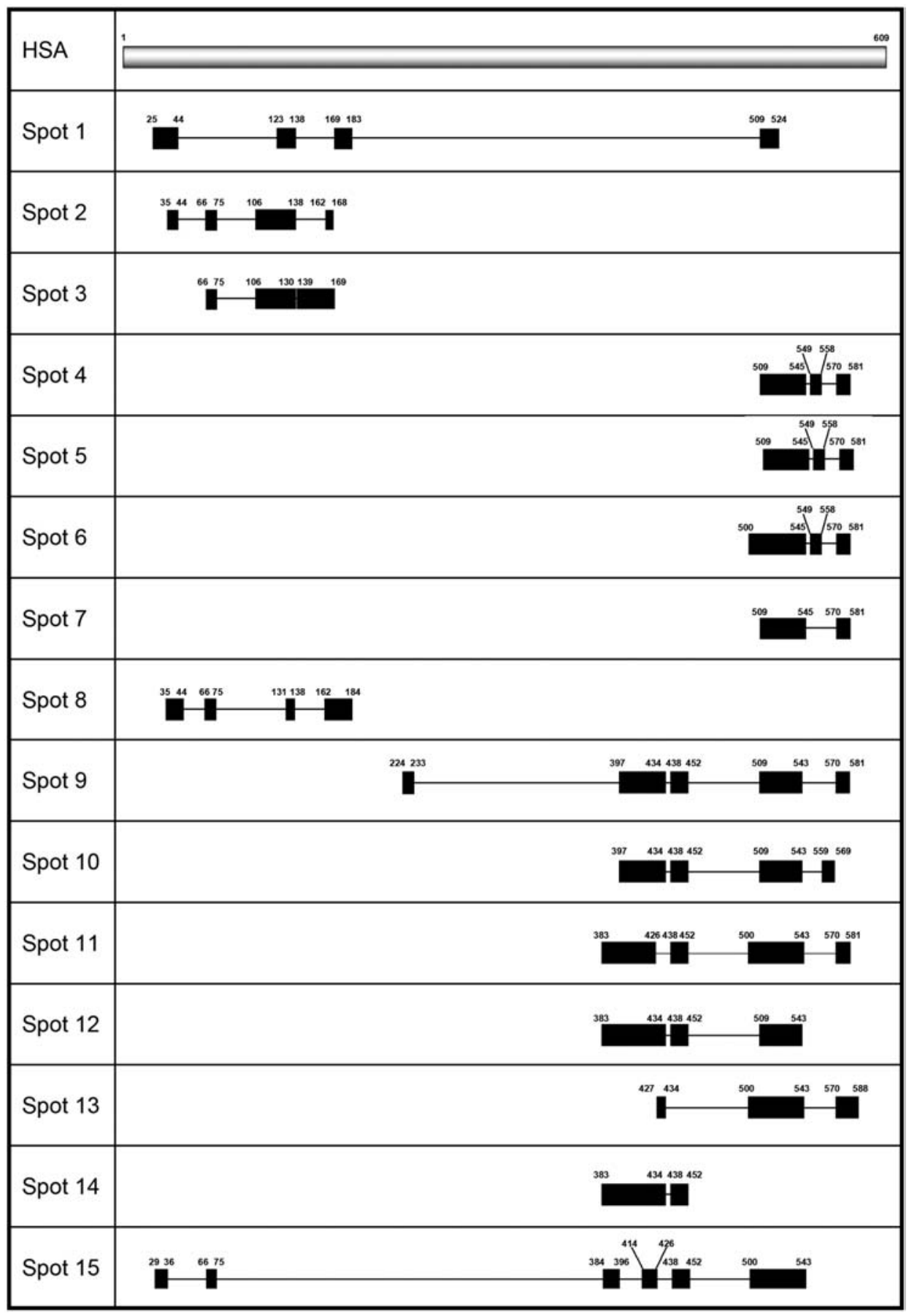

Figure 4 Schematic representation of serum albumin peptide composition as assigned by mass spectrometry to spots that were recovered from $2 \mathrm{D}$ gels.

The spot numbers correspond to numbers in Table 1, Figures 1 and 2. HSA, human serum albumin.

molecular weight proteins, and as fragments of albumin.

\section{References}

1. Maack T, Hyung Park C, Camargo MJ. Renal filtration, transport, and metabolism of proteins. In: Seldin D, Giebisch G, editors. The kidney: physiology and pathophysiology. New York: Raven Press, 1985:1773-803.
2. Bianchi C, Donadio C, Tramonti G, Auner I, Lorusso P, Deleide $G$, et al. Renal handing of cationic and anionic small proteins: experiments in intact rats. Contr Nephrol 1988;68:37-44.

3. Johanson BG, Ravnskov U. The serum level and urinary excretion of $\alpha 2$-globulin, $\beta 2$-microglobulin and lysozyme in renal disease. Scand J Urol Nephrol 1972;6:249-56.

4. Itoh $\mathrm{Y}$, Enomoto $\mathrm{H}$, Takagi $\mathrm{K}$, Kawai T. Clinical usefulness of serum $\alpha 1$-microglobulin as a sensitive indicator for renal insufficiency. Nephron 1983;33:69-70.

5. Grubb A, Simonsen O, Sturfelt G, Truedsson L, Thysell H. Serum concentration of cystatin $C$, factor $D$, and $\beta 2$-micro- 
globulin as a measure of glomerular filtration rate. Acta Med Scand 1985;218:499-503.

6. Schardijn GH, Statius van Eps LW. $\beta 2$-microglobulin: its significance in the evaluation of renal function. Kidney Int 1987;32:635-41.

7. Priem $F$, Althaus $H$, Birnbaum M, Sinha $P$, Conradt HS, Jung K. $\beta$-trace protein in serum: a new marker of glomerular filtration rate in the creatinine-blind range. Clin Chem 1999;45:567-8.

8. Tramonti G, Ferdeghini M, Annichiarico C, Norpoth M, Donadio C, Bianchi R, et al. Relationship between renal function and blood level of chromogranin A. Ren Fail 2001;23:449-57.

9. Donadio C, Lucchesi A, Ardini M, Giordani R. Serum levels of beta-trace protein and glomerular filtration rate-preliminary results. J Pharmaceut Biomed Anal 2003; 32:1099-104.

10. Osicka TM, Comper WD. Characterization of immunochemically non-reactive urinary albumin. Clin Chem 2004; 50:2286-91.

11. Terawaki $H$, Yoshimura $K$, Hasegawa $T$, Matsuyama $Y$, Negawa T, Yamada K, et al. Oxidative stress is enhanced in correlation with renal dysfunction: examination with the redox state of albumin. Kidney Int 2004;66:1988-93.

12. Aresta $A$, Calvano CD, Palmisano F, Zambonin CG, Monaco $A$, Tommasi $S$, et al. Impact of sample preparation in peptide/protein profiling in human serum by MALDITOF mass spectrometry. J Pharm Biomed Anal 2008;46: 157-64.

13. Laemmli UK. Cleavage of structural proteins during the assembly of the head of bacteriophage T4. Nature 1970; 227:680-5.

14. Yan JX, Wait R, Berkelman T, Harry RA, Westbrook JA, Wheeler $\mathrm{CH}$, et al. A modified silver staining protocol for visualization of proteins compatible with matrix-assisted laser desorption/ionization and electrospray ionization mass spectrometry. Electrophoresis 2000;21:3666-72.

15. Görg A, Postel W, Gunther S. The current state of twodimensional electrophoresis with immobilized pH gradients. Electrophoresis 1988;9:531-46.

16. Hellman U, Wernstedt C, Gonez J, Heldin CH. Improvement of an "In-Gel" digestion procedure for the micropreparation of internal protein fragments for amino acid sequencing. Anal Biochem 1995;224:451-5.

17. Soskic V, Gorlach M, Poznanovic S, Boehmer FD, Godovac-Zimmermann J. Functional proteomics analysis of signal transduction pathways of the plateletderived growth factor beta receptor. Biochemistry 1999; 38:1757-64.

18. Schiffer E, Mischak H, Vanholder RC. Exploring the uremic toxins using proteomic technologies. Contrib Nephrol 2008;160:159-71.

19. Molina H, Bunkenborg J, Reddy GH, Muthusamy B, Scheel PJ, Pandey A. A proteomic analysis of human hemodialysis fluid. Mol Cell Proteomics 2005;4:637-50.

20. Osicka TM, Houlihan CA, Chan JG, Jerums G, Comper WD. Albuminuria in patients with type 1 diabetes is directly linked to changes in the lysosome-mediated degradation of albumin during renal passage. Diabetes 2000;49:1579-84.

21. Candiano G, Musante L, Bruschi M, Petretto A, Santucci L, Del Boccio $P$, et al. Repetitive fragmentation products of albumin and alpha 1- antitrypsin in glomerular diseases associated with nephrotic syndrome. J Am Soc Nephrol 2006;17:3139-48.

22. Candiano G, Musante L, Petretto A, Bruschi M, Santucci $L$, Urbani $A$, et al. Proteomics of plasma and urine in primary nephrotic syndrome in children. Contrib Nephrol 2008;160:17-28. 